\title{
Kalang, Tinjauan Historis-Antropologis
}

\section{Bambang Sulistyanto}

Keywords: inscription, historical, carpenter, Kalang, Old Java

\section{How to Cite:}

Sulistyanto, B. Kalang, Tinjauan Historis-Antropologis. Berkala Arkeologi, 14(2), 109-114. https:// doi.org/10.30883/jba.v14i2.708

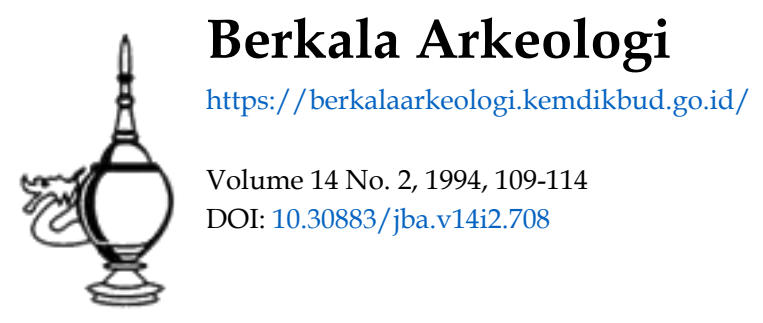

\section{(c) (1) (2)}

This work is licensed under a Creative Commons Attribution-NonCommercial-ShareAlike 4.0 International License. 


\title{
KALANG, TINJAUAN HISTORIS-ANTROPOLOGIS
}

\author{
Bambang Sulistyanto \\ (Balai Arkeologi Yogyakarta)
}

\section{Permasalahan}

Dalam berbagai prasasti Jawa kuna, banyak sekali dijumpai istilah Kalang yang pengertiannya seringkali dihubungkan dengan profesi di bidang perkayuan atau tukang kayu. Pengertian tersebut ditarik dari suatu realitas terhadap keberadaan "wong Kalang" di masa kemudian yaitu sekelompok orang yang hidup di tepi hutan di beberapa tempat di Jawa sebagai penebang kayu.

Sisa-sisa dari sekelompok orang yang di sebut "wong Kalang" itu, pada awal abad yang lalu dapat ditemukan hidup di sekitar pegunungan yang meliputi daerah sekitar pantai selatan pulau Jawa dan pantai utara pulau Jawa Tempat-tempat tersebut di antaranya Cilacap, Gombong, Yogyakarta, Surakarta, Cepu, Bojonegoro (Altona, 1923: 528) Pada masa sekarang ini, tidak dapat lagi ditarik batas secara tegas tempat kediaman "wong Kalang", karena mereka telah berbaur dengan masyarakat di sekitamya.

Pengamatan antropologis khususnya terhadap tradisi atau adat kebiasaan mereka, dapat dibedakan dengan kebiasaan orang Jawa pada umumnya. Hal tersebut disebabkan "wong Kalang" memiliki Tradisi yang khas yang disebut upacara obong, yaitu upacara kematian, penghormatan terhadap roh leluhur dengan cara membakar puspa atau boneka serta sesajian lainnya yang diteruskan dengan melabuhkan abunya ke laut. Upacara obong tersebut mengingatkan pada upacara sradha (Majapahit) atau ngaben (di Bali). Pelaksanaan upacara tersebut terakhir di selenggarakan pada tanggal 8 Agustus 1978 oleh orang Kalang di Desa Ngotho, Kelurahan Bangunjiwo, Sowon, Bantul, Yogyakarta.

Permasalahannya adalah apakah wong kalang itu identik dengan kalang sebagaimana sering disebut dalam berbagai prasasti Jawa kuna. Istilah Kalang sudah muncul dalam prasasti Kuburan Candi $831 M_{1}$ pada masa pemerintahan Rakai Garung. Baris 16 menyebutkan ... lengkep Kalang ri ngunung... Menurut Goris (1930:161) istilah Kalang tersebut berarti menyatakan jabatan dari kelompok Kalang atau pertukangan kayu.

Istilah Kalang berianjut sampai pada prasast-prasasti periode Jawa Timur. Istilah Kalang sering pula dilengkapi dengan kata tuha (kalang) yang mmyiratkan pada suatu pejabat atau pemimpin kelompok kalang. Di samping itu, Kalang sering pula diawali dengan kata yang menyata- kan profesionalitas pande Kalang (Nastiti, 1982 : 33). Bahkan istilah Kalang seringkali dilengkapi dengan nama pejabat dari kelompok orang Kalang itu sendiri. Dalam konteks demikian inı, kalang diartikan sebagai pejabat desa yang bertugas di bidang perkayuan. Prasasti Rumbiga baris ke 10 misalnya, ...rumbiga $r i$ kan kalan pu bansi rama ni anjak... (Supraptiningsih, 1978:43).

Istilah kalang dalam prasasti, menunjukkan peranan dan kedudukan mereka cukup penting. Bahkan tuha kalang sebagai wakil desa tertentu dari kelompok kalang, seringkali diundang untuk menghadiri upacara penetapan sima. Dalam konteks demikian inilah Buchari (1977:8) mempertanyakan apakah kalang dalam prasasti identik dengan wong kalang pada zaman kemudian? sebab pengertian tukang kayu banyak pula disebut dalam prasasti dengan istilah lain yaitu undehagi (Sumadio, 1974:214)

Menurut M.M. Sukarto K. Atmodjo, pengertian kalang sebenamya masih kabur. Apakah pande kalang itu sama dengan tuha kalang? (Sukarto,1986:56). Sukarto lebih lanjut menjelaskan bahwa kalang atau kalangan memiliki pengertian suatu tempat untuk keperluan menyabung hewan, adu ketangkasan dalam suatu upacara tertentu, di mana hal tersebut masih dijumpai di Bali.

Demikianlah tulisan ini akan mencoba membahas pengertian kalang, melalui kajian historis-antropologis. Ini berarti kalang tidak hanya dilihat dari segi pengertiannya, melainkan justru cenderung ditarik suatu gambaran historis peranan orang kalang sebagai kelompok manusia yang hidup dari zaman ke zaman. Tentu saja permasalahan itu semua tidak dapat dibahas secara terperinci, tetapi beberapa segi penting akan dicoba dikemukakan.

\section{Kalang Pada Masa Mataram Islam.}

Pada masa Mataram Islam golongan orang kalang muncul beberapa kali dalam pemberitaan Pada tahun 1640 misalnya, Sultan Agung me ngumpulkan sebagian orang kalang untuk diberi tempat tinggal yang menetap. Karena kemahirannya dalam pembuatan barang-barang dar kayu, beberapa di antaranya dijadikan abdi dalem atau hamba raja dengan tugas khusus untuk mendirikan bangunan-bangunan di lingkungan keraton seperti masjid, istana, dan rumah (Altona, 1923: 527 ) 
Darı pemberitaan tersebut, memberikan asumsi bahwa golongan orang kalang merupakan golongan yang terpisah dari masyaskat Jawa sekitarnya. Ada kemungkinan kelompok mereka waktu itu masih tinggal di tepi-tepi hutan sebagai tukang kayu. Dari kelompok minoritas, masyarakat yang terpisah dari sekitarnya, kemudian dikumpulkan bahkan beberapa di antaranya ada yang di angkat menjadi abdi dalem, hal ini memperlihatkan adanya perubahan status mereka.

Di keraton Surakarta, tugas dan kewajiban golongan orang kalang tertuang dalam Anggeran geladag bab XII - XVII. Antara lain mereka berkewajiban menyediakan bahan bangunan berupa kayu jati yang ditebang dari hutan. Selain, mengerjakan bangunan-bangunan keraton, mereka juga melaksanakan pendirian bangunan tempat kediaman putera dan kerabat raja. Tugas di bidang perkayuan itu, dirinci antara lain penebangan di hutan dan pengangkutannya di tempat bangunan akan didirikan. Biasanya jika bangunan-bangunan itu berlokasi di sekitar keraton, kayu jati dikumpulkan di alun-alun

Golongan orang kalang tersebut diperintah oleh seorang bupati berpangkat Tumenggung. Sebagal mata pencarian pokok, mereka diperkenankan menebang kayu di hutan untuk dijual atau dibuat barang kerajinan. Tetapi mereka juga mendapat kewajiban membayar pajak sebesar satu rınggit, lebih besar darı pajak yang dikenakan pada orang Jawa pada umumnya (Jbid: 529).

Hal tersebut menunjukkan keistimewaan pejabat yang menguasai orang kalang. Pejabat yang menguasainya berpangkat Wedana, ia berhak mendapat sebutan Tumenggung. Padahal pangkat Wedana merupakan sebutan Ngabehi. Jabatan Wedana bagi orang kalang tidak pernah diserahkan kepada orang kalang sendiri (Tim Penelitian golongan orang-orang Kalang, 1973:432). Jadi, hanya orang "Jawa" dan Bupati Kalang-lah yang berhak menduduki jabatan Wedana.

Pada abad XVIł jumlah orang kalang meningkat. Hal ini terbukti pada tahun 1739 Paku Buwono II mengangkat Sumodiningrat menjadi tumenggung di Sedayu, dan menugaskan untuk memerintan golongan kalang (sejumlah $6.000 \mathrm{ke-}$ luarga). Selain itu juga divuktikan pada perjanjian Gianti (tahun 1755), Susuhunan Surakarta dan Sultan Yogyakarta memerintah golongan kalang sebanyak 3.000 keluarga (Pontjosutirto, 1988:7).

Dari uratan di atas, dapat ditarik pengertian, bahwa peranan golongan orang kalang terbukti cukup besar. Kemahirannya dalam bidang perkayuan dimanfaatkan oleh raja untuk mendirikan bangunan keraton sekaligus pembuatan berbagai peralatan teknis bahkan termasuk pembuatan perahu Serat Babad Mengeti Lelampahan Dalam SOISKS Pakoe Boewono Kaping $V$ memperkuat anggapan itu. Raja mempercayakan pembuatan perahu pesiar yang besar kepada abdi dalem kalang. Perahu yang besar itu direncanakan akan dipergunakan mengantar keluarga keraton ke Pamekasan (Serat Babad, 9)

Di keraton Surakarta abdi dalem kalang bekerja sama dengan abdi dalem narawreksa (Lelono,1989:2). Mereka tinggal di suatu kampung (sekarang bemama Kalangan). Pada perkembang selanjutnya abdi dalem kalang dimasukkan ke dalam suatu jawatan kartipura, yaitu jawatan yang mengurusi bangunan keraton seka. ligus bertanggung jawab pada masalah kebersihan dan perawatan bangunan. Di Mangkunegaran jawatan itu dinamak an Kartisana (Tim Peneliti Golongan orang Kalang, 1973: 45)

Pada masa selanjutnya tugas golongan orang kalang, mengalami perkembangan. Bahkan mereka ikut bertanggung jawab atas keselamatan bangunan. Seperti misalnya pada waktu ada keramaian keraton (grebeg Mulud atau grebeg besar), abdi dalem kalang bertugas memanjat di atas atap menjaga timbulnya kebakaran (lbid: 46).

\section{Kalang Dalam Zaman Kompeni}

Pada zaman kompeni berkuasa di Jawa tugas dan peranan golongan orang kalang lebih kompleks. Kebutuhan kompeni akan kayu Jati untuk pembangunan kota Batavia dan kota lainnya dan untuk kebutuhan galangan-galangan kapal, mengakibatkan nama kalang tercantum dalam surat-surat resmi atau dalam dagresgister

Bukti tertua surat resmi dari Kompeni yang menyebut orang kalang, kemungkinan yang dibuat oleh Jac. Couper dari Jepara. Dalam surat itu dikatakan antara lain; bahwa di hutan-hutan daerah pegunungan Rembang dan Pati ada sejumlah orang kalang yang mahir di bidang perkayuan. Mereka bersedia menebang kayu $d_{1}$ hutan yang ditentukan. Surat Jac. Couper itu ditujukan pada Hoge Regering ditulis oleh de Jonge tanggal 4 November 1675 (de Jonge, 1975: 193)

Dari berita tersebut dapat diketahui, bahwa pada waktu itu terdapat banyak golongan orang kalang yang berdiam di sekitar hutan sebagaı penebang kayu. Kemampuan mereka dalam bidang perkayuan dimanfaatkan oleh pihak kompenı untuk pembuatan berbagai sarana guna memperkokoh kekuasaannya di Jawa.

Tetapi tiga tahun kemudian berdasarkan memori Speelman yang tertulis tahun 1678 dika. takan, bahwa kesediaan golongan orang kalang tersebut mendapat rintangan dari pemimpin mereka. Mereka tidak diperbolehkan menyerahkan kayu kepada pihak Kompeni. Maka terpaksa pıhak Kompeni minta bantuan kepada Susuhunan agar berkenan turun tangan. Tetapi usaha tersebut tidak membawa perubahan, bahkan Sunan berpihak kepada golongan orang kalang. 
Satu buktı bahwa golongan orang kalang tidak mau bekerja sama dengan pihak Kompeni, tercantum dalam Dagregisier tanggal 22 Oktober 1680 yang menerangkan, bahwa mereka segan bekerjasama dengan Kompeni dengan alasan takut mendapat hukuman badan dari pimpinan mereka (Ibid, 47 )

Nasib golongan orang kalang mengalami perubahan tahun 1743 saat diadakan perjanjian antara Susuhunan Paku Buana II dengan pihak Kompeni, setelah Kompeni berhasil mengakhin pemberontakan Mas Garendi. Dalam perjanjian itu di antaranya ditetapkan, orang Jawa tetap diperintah oleh bupati-bupati. sedangkan orangorang golongan kalang merupakan golongan terpisah dari masyarakat "Jawa" umumnya. Selain itu, para bupati diwajibkan mengirimkan sejumlah orang kalang yang diperlukan oleh Kompeni untuk pembuatan maupun perbaikan kapal-kapal di galangan-galangan (lbid,48)

Menurut P. J. Veth (1907:103) orang kalang yang berada di dalam wilayah kekuasaan Kompenı waktu itu (1743) sekitar 2.000 keluarga. $\mathrm{Di}$ Surabaya 250 keluarga, Pasuruhan 50 keluarga, Pati 250 keluarga, Demak 1000 keluarga, Kendal 250 keluarga, Pekalongan 800 keluarga dan tegal 180 keluarga. Data tersebut, menunjukkan golongan orang kalang merupakan golongan minoritas yang nasibnya berubah-ubah. Nasib golongan orang kalang ditentukan oleh penguasa, selain itu berkaitan juga dengan situasi perkem. bangan politik waktu itu. Muncul dan campur ta. ngan Kompeni dalam pemerintahan, mengakibatkan golongan orang kalang semakin tertekan. Penetrasi dan pihak Kompeni ini akhimya meng. akibatkan golongan orang kalang berontak. Pemberontakan goiongan orang kalang itu terjadi pada tahun 1770 di daerah Pati. Akibatnya pihak Kompeni kehilangan seorang kopral dan empat orang mati terbunuh. Begitu juga gudang mesiu dapat terbongkar dan gudang beras milik Residen dibakar. Di lain pihak golongan orang kalang diketahul, sekitar 10 orang mati terbunuh dan sepuluh orang lagi ditawan (Zwart, 1939: 258).

Dampak dari pembrontakan tersebut, pada tahun itu juga diadakan lagi perbaruan peraturan yang antara lain menyatakan, bahwa golongan orang kalang berhak memilih pemimpin mereka sendiri dan mereka memiliki hak-hak seperti semula. Bahkan ketika Daendels mengadakan reorganisasi pemerintahan di pantai Timur Laut Jawa, antara lain menetapkan agar para bupati tidak lagi memungut pajak dari golongan orang katang. Bahkan orang kalang diberikan hak untuk mengambil kayu dari hutan untuk keperluan peralatan pertanian. Satu larangan bagi orang kalang yaitu mengambil atau menebang kayu jati yang hanya diperuntukkan bagi pemerintah. Per- nyataan ini tercantum dalam plakat tanggal 21 Agustus 1808 (de Yonge, Op cit, 198)

\section{Kalang Pada Masa Sekarang}

Sebagaımana telah disinggung di muka, keberadaan "orang kalang" pada masa sekarang sukar ditemukan. Sebab mereka sudah berbaur dengan masyarakat Jawa pada umumnya. Golongan orang kalang memiliki sifat mudah menyesuaikan diri dan bersıkap terbuka. Kedudukan mereka tidak sejelas golongan orang Tengger: atau Badui, yang hidup mengelompok memisah. kan diri dari masyarakat.

Pada mulanya mereka mempunyai adat is. tiadat sendiri yang khas, namun lama-kelamaan luntur dan menyesuaikan din dengan kebudaya. an masyarakat di sekitamya. Karena itu sepert! hainya masyarakat Jawa, pada umumnya mereka memeluk agama Islam. Begitu juga mate pencarian, bahasa, maupun cara berpakaian tidak ada perbedaan dengan orang Jawa Tetapı pengamatan antropologis khususnya terhadap tradisi yang masih mereka pertahankan, dapat dikenali secara jelas identitas orang kalang. Tradisi yang khas inilah yang membedakan antara orang kalang dengan orang Jawa pada umumnya Tradisl yang dimaksud adalah upacara obong, yartu upacara kematian untuk menghormatı roh leluhur dengan cara membakar puspasarira dan perlengkapan sesaji lainnya

Upacara obong tersebut mirip dengan upacara sradha pada masa Majapahit, sebagaimana diceritakan dalam Negarakertagama pupuh 63 67 (Slametmulyana, 1979:304-307). Perbandingan antara upacara obong dan sradha, ada tiga hal yang esesial dan memperlihatkan kemiripan kedua upacara tersebut.

1. adanya puspa, yaitu boneka sebagal simbol ruh si mat. Dalam upacara obong puspa itu dibuat dari kayu jatı dengan tinggı sekitar 35 $\mathrm{cm}$ lebar $15 \mathrm{~cm}$ Puspa itu dilengkapı dengan pakaian dan perhiasan sebagaimana layaknya manusia hidup. Dalam upacara Sradha, puspa atau simbol ruh yang mati tersebut dibuat darı rangkaian bunga

2. adanya pancaka, yartu bangunan rumah-rumahan untuk menyemayamkan puspa sebelum akhirnya dibakar dan abunya dibuang ke laut Pancaka dalam upacara obong tersebut dibuat dari rangka bambu berdinding dan bera. tapkan daun ilalang. Pancaka berukuran tinggı 1 meter dengan luas $2 \times 2$ meter

3. proses jalannya ritual dilakukan secara prasawyam, suatu proses ritual klasik yang berkaitan dengan kematian

Upacara obong sampai sekarang masin $d$. pertahankan, terakhir dilakukan pada tanggal 8 Agustus 1978 oleh orang kalang di Desa Ngotho Bangunjiwo, Sewon, Bantul, Yogyakarta (Lelono, 
1989:5). Sesuai dengan perkembangan zaman upacara khas ini juga mengalami perubahan, tetapi dasar dan tujuan masih dipegang teguh. Perubahan tidak prinsipil terjadi misalnya, upacara tidak harus tepat dilakukan pada 1.000 hari, me. lainkan boleh ditangguhkan menunggu sampai biaya cukup tersedia

Secara pisık orang kalang sukar dibedakan dengan orang Jawa, namun secara kultur menurut Buchan masih dapat diamatı meskipun tidak begitu tegas. Ciri-ciri orang kalang menurut Buchari (1985:11-13) yaitu antara lain; rumah mereka berpagar tinggi, gemar memelihara anjing, senang memakai nama Mulya atau Perwira, kebanyakan bekerja sebagai wiraswasta. Selain itu, ciri orang kalang meskipun tidak dinyatakan secara jelas, menganut endogam dalam pengertian genetis. Terutama pihak lelaki, harus mencari jodoh dari kalangan orang kalang sendiri. Bagi pihak perempuan, ketentuan itu agak longgar (Tim Peneliti Fak.Hukum UGM, 1973:51). Hal itu mungkın dimaksudkan agar hubungan kekeluargaan mereka lebih erat, di samping untuk mempertahankan eksistensi keberlangsungan orang kalang itu sendin supaya tidak punah

Pada masa sekarang golongan orang kalang bermukim tersebar diberbagai kota di antaranya di sepanjang pantai selatan Jawa Tengah, pantai utara Jawa Tengah dan Jawa Timur, sepertı Tegal, Pekalongan, Semarang, Demak, dan Pati. Di Jawa Timur mereka tinggal di Surabaya, Bangil, Pasuruan dan Banyuwangi. Di Jawa Tengah Selatan mereka tinggal di Ambal, Gombong, Karanganyar, dan Yogyakarta (Tengalgendu, Kotagede, Imogiri, Srandakan, Mangiran dan Ngotho) (Buchari; Ibid:4).

Berdasarkan pengamatan, golongan orang kalang pada masa sekarang lebih banyak terjun di bidang perdagangan, sebagian lagi menekuni profesı bidang perkayuan, perak, dan lain sebagaınya. Anehnya mereka tidak banyak yang menjadi pegawai negeri, justru sebagian besar memilih wiraswasta dan dalam bidang ini mereka banyak yang sukses dan merjadi orang yang terpandang secara materı. Sebagai contoh, beberapa toko di Malioboro dan beberapa hotel di Yogyakarta, milik keluarga kalang (Buchari; Ibid).

Sekarang ini mereka hidup terpisah, tetapi dalam hal kekerabatan sangat erat dan saling membantu antar keluarga yang lemah. Bahkan hubungan mereka sesama anggota golongan sangat kuat. Sebagai bukti, misalnya di beberapa kota mereka mendirikan organisasi kekeluargaan. Di Jakarta organisası mereka bemama "Kolang Mulyo', sedangkan di Yogyakarta, persatuan mereka dinamakan "Keluarga Tresno" (Tim Peneliti FH-UGM, ibid: 63)

\section{Peranan Golongan Orang Kalang}

Berdasarkan data sebagaimana digambarkan tersebut di depan, dapattah diketahui bahwa istilah kalang dalam berbagai prasastı Jawa kuno mempunyai pengertian yang berkaitan dengan profesi dalam bidang perkayuan. Namun perlu juga diingat, bahwa data etnohistoris memberikan pengertian lain, bahwa kalang dapat berart suatu profesi yang berhubungan dengan upacara "persabung-an" binatang. Hal ini dapat dibuktikan pada masa pemerintahan Paku Buwono I di Su. rakarta atau Yogyakarta, abdi dalem kalang diberı tugas khusus memimpin upacara rampogan (Graff,1949:281). Bangunan untuk persabungan binatang itu di Bali disebut Wantilan yang tentunya ada petugas khusus, mengingat persa. bungan hewan (ayam) merupakan salah satu rangkaian upacara keagamaan.

Oleh karena itu istilah kalang dalam pra. sasti perlu diterjemahkan secara hati-hati dengan melihat konteks kalimatnya. Apalagi dalam berbagai prasasti ada istilah laın untuk menyebut pertukangan kayu yaitu undahagi. Demikinan pula tuha kalang dalam prasasti sering diundang dalam upacara penetapan sima. Kehadiran Tuha Kalang tersebut, mungkin saja bukan hanya sekedar sebagai saksi penetapan suatu sima, melainkan ikut pegang peranan penting dalam suatu upacara

Serangkaian data historis memperlihatkan bahwa pada masa Mataram Islam tidak sedikit golongan orang kalang yang diangkat menjadı abdi dalem kerajaan. Maka pengertian tuha kalang dalam prasasti mengungkapkan pejabat atau pemimpin dari kelompok kalang adalah orang kalang itu sendiri Namun data historis menunjukkan bahwa golongan orang kalang tsdak diperkenankan oleh raja menjabat suatu jabatan tertentu. Maka kemungkinan yang dimaksud tuha kalang dalam prasastı tidak didudukı oleh kelompok dari orang kalang itu sendiri Jadi jabatan tuha kalang tersebut dipegang oleh orang "Jawa" yang secara formal memiliki status atau derajad yang dinggap lebih tinggi.

Dari manakah asal usul orang kalang itu? Hingga kinı masih banyak silang pendapat di antara para sarjana. Pendapat yang mungkın cukup relevan, dikemukakan oleh $E$. Ketjen, bahwa pada hakekatnya mereka adalah suku bangsa Jawa. Adapun sebab-sebab mereka tersısih, karena akibat adanya sistem kemasyarakatan pada masa Hindu yang mengenal adanya empat kasta Golongan orang kalang yang memiliki profesi kasar dimasukkan ke dalam golongan yang berderajat rendah yang pada akhirnya tersıngkir hidup di tepi hutan (Ketjen, 1928 :425)

Kemahırannya dalam bidang perkayuan menjadikan golongan orang kalang diperlukan dari zaman ke zaman. Pada masa Mataram 
Isiam mereka banyak dimanfaatkan dalam pendirian bangunan-bangunan di lingkungan keraton termasuk masjid dan makam, dan pada masa pengaruh Hindu, golongan ini punya peranan besar dalam pendirian candi-candi atau bangunan profan dl lingkungan kerajaan. Sayang sekali bukti arkeologis tentang hal ini sukar diperoleh

Dalam perkembangan selanjutnya, keadaan golongan orang kalang berubah, karena sebagian telah diangkat sebagai abdi dalem keraton yang mempunyai tugas khusus di bidang pertukangan sebagaimana diperlihatkan dalam Anggeran Geladag Bab 12-17. Dalam konteks ini, derajad mereka meningkat karena mendapat pengakuan secara formal sebagai hamba raja.

Ada kemungkinan meningkatnya status sosial tersebut disebabkan karena perubahan kebudayaan $\mathrm{Hal}$ tersebut karena pengaruh Islam berkembang kuat dengan kebudayaan yang tidak mengenal sistem kasta. Dengan demikıan perubahan kebudayaan mempengaruhi nasib dan kedudukan golongan orang kalang. Mereka kemba$i$ bergabung dalam masyarakat ramai. Akan tetapi hal itu jelas tidak mudah, karena mereka membutuhkan proses waktu yang panjang untuk mendapatkan kedudukan yang sejajar dengan masyarakat di sekelilingnya seperti sekarang

Ketika Kompeni berkuasa di Jawa, peranan golongan orang kalang cukup besar dalam pembuatan kapai-kapal di galangan sebagaimana diperlihatkan oleh surat resmi yang dibuat oleh Jac. Couper tertanggal 4 November 1675 (de Yonge, 1875 193) Bahkan, golongan orang kalang dimanfaatkan oleh Kompeni untuk membantu peperangan. Bukti tentang hal inı dapat dilihat $\mathrm{mi}$. salnya pada peristiwa tahun 1679, para bekel yang membawahi golongan orang kalang mendapat hadiah darı Kompeni karena mereka turut berperang memadamkam pemberontakan Trunojoyo di Kedirı. Golongan orang kalang tıdak mengangkat senjata, tetapı peranan mereka sangat besar sebagai tukang-tukang pedati yang bagus dalam pasukan pengangkut Anthoni Hurdt (Zwart. op cit, 259)

Dalam hubungannya dengan hal peperangan golongan orang kalang dewasa ini dapat disamakan dengan barisan zeni. Zeni merupakan suatu pasukan khusus yang memilikı tugas mengurus persenjataan dan perlengkapan lain, misalnya membuat atau memperbaiki jembatan, dan jalan-jalan yang rusak untuk memperlancar jalannya pasukan

Pada masa Daendels berkuasa di Jawa kedudukan golongan orang kalang lebih mapan lagı Mereka tıdak dikenakan pungutan pajak, namun harus taat kepada pihak Kompeni Sementara berdasarkan Plakat tanggal 21 Agustus 1808 , diketahul golongan orang kalang diperkenankan menebang kayu untuk pembuatan pedati, kecuali kayu-kayu yang dilarang yang akan dipergunakan sendiri oleh pemerintah (de Yonge, $O p$ cit. 198)

Demikian peranan golongan orang Kalang cukup punya andil besar khususnya dalam bi. dang pertukangan dari zaman ke zaman Karena kemahirannya di bidang perkayuan posısi dan kedudukan mereka meningkat Meningkatnya status sosial golongan orang kalang tersebut tidak lepas dari situasi politik dan perubahan kebudayaan masa yang bersangkutan.

\section{KEPUSTAKAAN}

Altona,1923, Over de Orspring der Kalang Batavia, Denhaag Albrecht \& Nijhpff.

Bambang Soemadio,(ed).,1984 Jaman Kuna (awal M-1500 M) Sejarah Nasional II Ja. karta : PN Balai Pustaka

Boecharı. 1977. Manfiaat Studı Bahasa dan sastra Jawa kuna ditinjau darı segi sejaran dan arkeologi. Majalah Arkeologi, Th 1 No 1 1977, hal 5 - 30 .

Buchari, S, 1985. Aspek Keagamaan dan Adat Dari Upacara Obong Pada Orang Kalang di Desa Ngoto. Laporan Penelitian Pengembangan ilmu Pengetahuan dan Teknologi, Yogyakarta. Belum diterbitkan

Goris, R., 1930 Inscriptie Koeboeran Candi TBG Jilid LXX, Batavia

Lelono, H. (1989). Upacara Kalang Obong (Suatu Tinjauan Etno-Arkeologi). Berkala Arkeologi, 10(1), 1-9.

https://doi.org/10.30883/jba.v10i1.533

Jonge,J.K.,1975. de Opkomst van het Neder. landsch Gezag in Oost Indie 's-Graven. hage: $M$. Nijhoof

Nastiti,Titi Suıti, dkk, 1982. Tiga Prasastı Darı Masa Balitung Jakarta Puslit Arkenas

Pontjosutıto,Soelarjo, 1988 Beberapa Hal Mengenai Orang Kalang. Makalah pada cera. mah di Museum Sonobudoyo, Yogyakarta

Sukarto,K.Atmodjo, 1986. Data Undahagi Dalam Prasasti Kuna dalam Diskusı IImiah Arkeo. logı, Yogyakarta 
Supraptiningsih., 1978. Prasasti Rumbiga 826 dan 827 Ç. Tinjauan Tentang Pungutan Pajak. Skripsi Fak. Sastra UGM.

Slametmulyana, 1979. Nagarakertagama dan Tafsir Sejarahnya. Jakarta : Bratara.

Veth P.J.,1907. Java, Geographisch, Ethnogisch, historich. Batavia.

Zwart W. De Kalangs als Houthakkers in dienst der Compagnie. TBG. Batavia: Museum Koninksplein W, vol. LXXIX, hal. 252 - 261. 